\title{
Cantilever Nanobiosensor Functionalized with Tyrosinase for Detection of Estrone and $\beta$-estradiol in Water
}

\author{
Alana Marie de Cezaro ${ }^{1}$ (D) $\cdot$ Aline Andressa Rigo ${ }^{1}$ (D) Janine Martinazzo ${ }^{1}$ (D) \\ Daniela Kunkel Muenchen ${ }^{1}$ (D) $\cdot$ Alexandra Manzoli $^{1}$ (D) Daniel Souza Correa ${ }^{2}$ (D) \\ Juliana Steffens ${ }^{1}$ (D) $\cdot$ Clarice Steffens ${ }^{1}$ (D)
}

Received: 27 May 2019 / Accepted: 11 November 2019/Published online: 29 November 2019

(C) Springer Science+Business Media, LLC, part of Springer Nature 2019

\begin{abstract}
This work aimed to develop cantilever nanobiosensor functionalized with tyrosinase enzyme to detect $17 \beta$-estradiol and estrone hormones. In this system, the tyrosinase enzyme was covalently immobilized by self-assembled monolayer onto the cantilever sensor surface. It was possible to verify that the high hormone concentration investigated resulted in high voltage response. The nanobiosensor presented a distinction between the concentrations evaluated and was verified sensitivities of 0.497 and $0.101 \mathrm{~V} / \mu \mathrm{g}$, limit of detection of 0.1 and $0.4 \mathrm{ng} / \mathrm{L}$ for the hormones $17 \beta$-estradiol and estrone, respectively. The device showed good reversibility and during 30 days of storage maintained about $99 \%$ of the original signal. The cantilever nanobiosensor applied in different water samples (ultrapure, river, tap, and mineral) showed good performance, so could be readily extended toward the on-site monitoring of the other trace small molecular pollutants in environmental water matrices.
\end{abstract}

Keywords Water Contaminants $\cdot$ Hormones $\cdot$ Enzyme $\cdot$ Sensitivity $\cdot$ Limit of detection

\section{Introduction}

The use of surface water for human consumption is the main reason for the warning about the water sources contamination. Among the contaminants commonly detected in superficial water bodies, the hormones stand out, in which even at low concentrations (ng/L or $\mu \mathrm{g} / \mathrm{L}$ )

Clarice Steffens

claristeffens@yahoo.com.br

1 Department of Food Engineering, URI Erechim, Av. Sete de Setembro, 1621, Erechim, RS 99709-910, Brazil

2 Nanotechnology National Laboratory for Agriculture (LNNA), Embrapa Instrumentação, P.O. Box 741, São Carlos, SP 13560-970, Brazil 
can cause changes in the endocrine system of aquatic organisms. They have low to moderate biodegradability in the environment, which contributes to increasing environmental prevalence and the impact on aquatic organisms and human health. The endocrine disruptors when present in the water at very low levels can provide several morphological, metabolic, and even sexual alterations in the body system [1].

The steroidal estrogens ( $17 \alpha$-ethinylestradiol, $17 \beta$-estradiol, and estrone) are included in the "watch list" of monitoring of substances of the EU Water Framework Directive (WFD) of the European Commission EU 2015/495. The monitoring of endocrine disrupting chemicals is very difficult because they are present in low concentrations and the detection limits of disposable analytical methods not meet the concentrations required [2]. The major methodologies employed in endocrine disrupting compounds determination are chromatography methods, although the analysis to be accurate is not easy and requires previous sample preparation.

An alternative method that has low limit of detection is the use of nanobiosensors. There are very sensitive to many compounds, even in extremely low concentrations, and do not require a sample preparation [3-5]. Nanobiosensors with submicron-sized dimensions are interesting devices that can detect nanoscale events and happenings due to the extremely large surface-tovolume ratio. This is interesting for cantilever nanobiosensors associated with biological recognition element (specific to the target analyte) that often interact with analyte on the surface. Cantilevers are typically rectangular-shaped bar anchored at one end, generally made with a silicon material, where the upper surface is coated with gold to provide a reflective surface, and in this surface can be attached functional groups with a biological element. The response of this device is the bending (surface stress) detected by the deflection of a laser beam. The efficiency in the analytes detection is associated with a specific layer (sensitive layer), as the enzymes [6,7]. Among the biological elements, the enzyme tyrosinase was effectively used in electrochemical biosensors in the determination of hormones in biological samples, foods, and environmental samples [8-11]. The tyrosinase has a III copper center with two copper atoms present in their active site that are interesting to bind and catalyze different kinds of enzymatic reactions (ortho-hydroxylation of monophenols and oxidation of odiphenols to o-quinones) and application in the hormones detection [12].

Cantilever nanobiosensors with tyrosinase enzyme for the measurement of $17 \beta$-estradiol and estrone have not been exploited until this moment in the literature. In this sense, this work aimed the cantilever nanobiosensor development for hormones detection (17 $\beta$-estradiol and estrone) and application in water samples (ultrapure, river, tap, and mineral). The cantilever surface was immobilized with the enzyme tyrosinase by the self-assembled monolayer. The sensitivity, limit of detection, and stability of the cantilever nanobiosensor were evaluated. The cantilever nanobiosensor surface was characterized in relation to roughness, topography, morphology, and functional groups.

\section{Material and Methods}

\section{Immobilization of the Cantilever Surface}

The cantilever of silicon material, coated with $70 \mathrm{~nm}$ of gold in the upper side, was commercially purchased (BudgetSensors), with $13.0( \pm 4) \mathrm{kHz}$ of resonance frequency and $0.2(0.07-0.4) \mathrm{N} / \mathrm{m}$ of spring constant. The self-assembled monolayer (SAM) technique was 
used for the enzyme immobilization (coated) onto the cantilever surface. For this, the cantilever was immersed in 16-mercaptohexadecanoic acid (16-MHD) solution, in the dark, for $16 \mathrm{~h}$. Next, rinse with distilled water to remove nonspecific, physically absorbed groups, and immerse in a solution (1:1, v:v) of 1-ethyl-3-(3-dimethylaminopropyl) carbodiimide hydrochloride (EDC) - N-hydroxysuccinimide (NHS) for $10 \mathrm{~min}$. After, the cantilever surface was rinsed with distilled water and dried. The enzyme immobilization was performed by the cantilever immersion in enzymatic solution at $4{ }^{\circ} \mathrm{C}$, thereby forming the sensitive layer. Commercial tyrosinase enzyme (2687 U/mg, Sigma Aldrich, USA) was diluted in $50 \mathrm{mM}$ potassium phosphate buffer, $\mathrm{pH} 6.5$, at $2 \mathrm{mg} / \mathrm{mL}$. Next, the cantilever nanobiosensor was washed with $50 \mathrm{mM}$ potassium phosphate buffer, $\mathrm{pH} 6.5$, and dried at room temperature $\left(25^{\circ} \mathrm{C}\right)$ for $15 \mathrm{~min}$.

\section{Characterization of the Cantilever Surface}

The cantilever surface was characterized by atomic force microscopy (AFM), scanning electron microscopy (SEM), and polarization modulation-infrared reflection absorption spectroscopy (PM-RAIRS) during the immobilization. The images of SEM were obtained in Jeol equipment (model - JSM6510, Japan), AFM in EasyScan 2 Flex AFM System (Nanosurf, Switzerland), and PM-RAIRS in a KSV spectrophotometer (model PMI 550 - KSV Instruments, Finland).

\section{Measurements with Cantilever Nanobiosensor}

The response of cantilever nanobiosensor functionalized with enzyme tyrosinase for $17 \beta$ estradiol and estrone was evaluated in the static mode using an AFM equipment (NanosurfC3000 Controller, Switzerland). The laser reflected from the cantilever surface reaches a sensitive position of the photo-detector. The distance traveled by the laser is proportional to the deflection and the signal obtained in voltage. The signal acquisition was through an image, in liquid medium, and in contact mode, using optical beam method. The images were converted into graphic, using Gwyddion software (version 2.45).

\section{Detection of Hormones}

Different concentrations $(0.0001,0.001,0.01,0.1,1$, and $10 \mu \mathrm{g} / \mathrm{L})$ of hormones $(17 \beta$-estradiol and estrone) were investigated. In addition, the response to ultrapure water was evaluated using the nanobiosensor. All measurements were performed in triplicate. During the analysis, the solutions were placed in increasing order of concentration of the hormone. In order to evaluate the interaction response of the nanobiosensor with the hormones $(1 \mu \mathrm{g} / \mathrm{L} 17 \beta$ estradiol and $1 \mu \mathrm{g} / \mathrm{L}$ estrone), a non-functionalized silicon cantilever was used.

The sensitivity, limit of detection (LD), reversibility, and stability (during 30 days of storage) of the cantilever nanobiosensor were evaluated. The limit of detection (lowest concentration of the analyte that can be distinguished) was calculated considering a confidence level (99.6\%) multiply by the standard deviation (blank) of the analytical curve. The sensitivity was obtained by the slope of the regression line of the analytical curve (cantilever nanobiosensor voltage vs. log of hormone concentration). The reversibility studies were conducted in a solution containing $1 \mu \mathrm{g} / \mathrm{L}$ of the hormone. During the storage (30 days), the cantilever nanobiosensor was maintained under refrigeration at $4{ }^{\circ} \mathrm{C}$. Before each analysis, the 
nanobiosensor remained $30 \mathrm{~min}$ at room temperature $\left(25^{\circ} \mathrm{C}\right)$ and calibrates the laser on the cantilever extremity. All analyses were done in triplicate, at $25^{\circ} \mathrm{C}( \pm 0.3) \mathrm{using} 1 \mu \mathrm{g} / \mathrm{L}$ of each hormone (singly), and evaluated every 15 days.

\section{Interference Study}

Interference study is a useful method to check the selectivity of the developed cantilever nanobiosensor functionalized with the tyrosinase enzyme. The behavior of the developed sensing system in the presence of interference was evaluated in the same way performed with the hormones. The interference substances were ascorbic acid, caffeine, and thiamine, commonly found in the aquatic environment. The substances were diluted in ultrapure water at a concentration of $1 \%$.

\section{Water Samples Collection and Analytical Procedures}

The water samples (river water) were collected from Rio Tigre River at Erechim City (RS, Brazil), with geographical coordinates: $27^{\circ} 37^{\prime} 54^{\prime \prime} \mathrm{S}$ and $52^{\circ} 16^{\prime} 52^{\prime \prime} \mathrm{O}$. The tap water samples were collected at Erechim City (RS, Brazil) with geographical coordinates: $27^{\circ} 64^{\prime} 93^{\prime \prime} \mathrm{S}$ $52^{\circ} 26^{\prime} 92^{\prime \prime} \mathrm{O}$. All samples were collected in clean glass bottles, maintained refrigerated $\left(4^{\circ} \mathrm{C}\right)$, and transported to the laboratory. The mineral water (table water) was obtained commercially from groundwater company with geographical coordinates $27^{\circ} 92^{\prime} 34^{\prime \prime} \mathrm{S}$ and $53^{\circ} 04^{\prime} 64^{\prime \prime} \mathrm{O}$. All samples were filtered with a $5 \mu \mathrm{m}$ filter paper (Nalgon) for removal of small leaves and suspensions and analyzed in the same day. Tap water and mineral water were used without any prior treatment. The response of cantilever nanobiosensor was evaluated in the same way performed with the concentrations of the hormones, measuring the voltage signal during the time.

\section{Results and Discussion}

\section{Characterization of the Nanobiosensor Surface}

As the sensing layer of the cantilever nanobiosensor has a significant impact on the detection performance, so the surface was evaluated by PM-RAIRS, AFM, and SEM. The PM-RAIRS was used to evaluate the effective functionalization and show the functional groups responsible for the modified properties of the gold surface, as well as to verify the adsorbed layer organization. Fig. 1 present a typical band $\left(2900 \mathrm{~cm}^{-1}\right)$ of the $\mathrm{CH}_{2}$ binding in the 16-MHD group. In addition, the layers resulted in an interaction between the compounds, thus reduce the band intensity $(\sim 50 \%)$ and confirm the efficiency of tyrosinase enzyme immobilization on the cantilever surface. The presence of 16-MHD with EDC/NHS can be observed in the spectra of $1650 \mathrm{~cm}^{-1}$ peak ascribed to the contribution of the $\mathrm{C}=\mathrm{O}$ stretching mode. This peak decrease in absorption at $1650 \mathrm{~cm}^{-1}$ was attributed to the loss of carbonyl groups $(\mathrm{C}=\mathrm{O})$ with the enzyme attachment. The peak at $2300 \mathrm{~cm}^{-1}$ is characteristic of $\mathrm{O}-\mathrm{H}$ stretching of carboxylic acid [13]. The PM-RAIS spectra confirmed that amine 3, characteristic of the enzyme, reacted with the NHS active esters, resulting in a modification of the peak at 2350 $\mathrm{cm}^{-1}$. The wavelength band at approximately $1050 \mathrm{~cm}^{-1}$ can be attributed to the symmetric stretching vibration of the $\mathrm{C}-\mathrm{O}-\mathrm{C}$ and glycosidic sites of the enzyme [14]. This band is maintained after the deposition of the enzyme on the gold surface. 


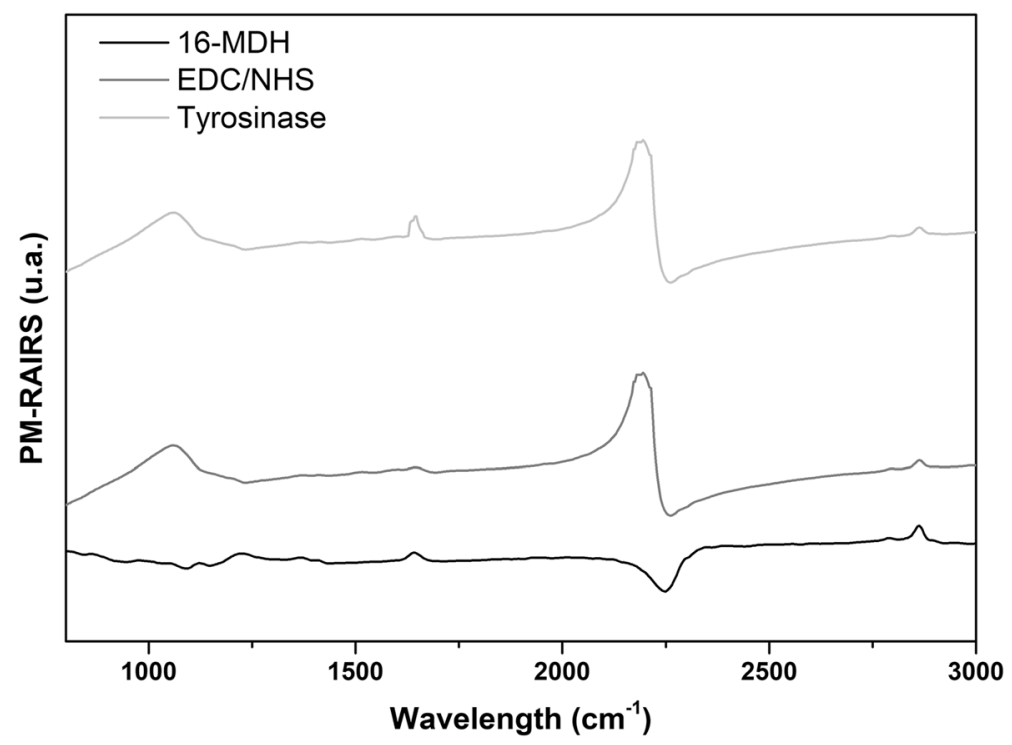

Fig. 1 PM-RAIRS of cantilever functionalization with 16-MHD, EDC/NHS, and tyrosinase enzyme

In the SEM and AFM images (Fig. 2) were verified an alteration in the surface topography and roughness with the layers deposition. The uncoated (non-functionalized) cantilever surface (Fig. 2a) has a more homogeneous and smooth area, with low roughness. The functionalized surfaces with 16-MHD (Fig. 2b) and EDC/NHS (Fig. 2c) showed groupings with irregularities, being more abundant in EDC/NHS layer. As 16-MHD acid has a long-chain molecule $[15,16]$, its deposition increased the surface roughness. This increase was also observed when the mixture of EDC/NHS crosslinking agents was added and occurred due to the changes in the functional groups exposed on the surface. These regions may be evidenced in Fig. 2 in both AFM and SEM images. The functionalized agglomerate from EDC/NHS presents average wide sizes of $0.3 \mu \mathrm{m}$.

The tyrosinase enzyme addition on the surface resulted in a homogeneous morphology, with more defined contours (Fig. 2d). The enzyme deposition resulted in a roughness
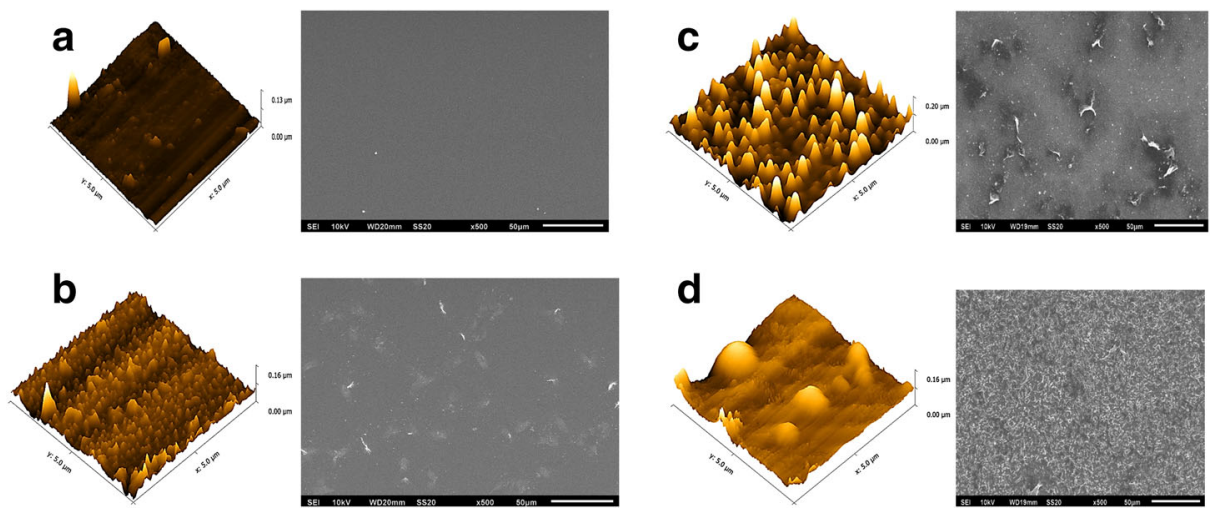

Fig. 2 Surface characterization by AFM and SEM of uncoated cantilever (a) and with functionalization of 16MHD (b); EDC/NHS (c); and tyrosinase enzyme (d) 
reduction, attributed to the filling of the voids that formed a more homogeneous layer. Thus, the difference in the roughness values is an indicative that there was deposition of material on the silicon surface.

\section{Response of the Cantilever Nanobiosensor}

Figure 3 shows the responses of the cantilever nanobiosensor functionalized with tyrosinase enzyme for ultrapure water and different concentrations $(0.0001$ to $10 \mu \mathrm{g} / \mathrm{L})$ of $17 \beta$-estradiol and estrone hormones. The nanobiosensor showed the lowest voltage signal for the low concentration of hormone investigated (Fig. 3). Already for ultrapure water, the voltage response was different of the hormones. The low voltage values can be associated with low hormone concentration in the solution, consequently implying in a smaller amount of the catalytic product, resulting from the enzyme-hormone interaction.

Figure 4 shows the voltage response of uncoated cantilever (white) exposed to an intermediate hormone concentration $(0.1 \mu \mathrm{g} / \mathrm{L})$ and ultrapure water. It is observed a linear response over the time, indicating that no has interaction of the cantilever with the hormones investigated. As the uncoated cantilevers do not have binding sites on the surface, it was not able to recognize the analyte of interest. For this reason, it is necessary to modify the surface, making them able to detect the hormones.

The biological sensing layer (tyrosinase enzyme) is an oxidase that has copper and catalyzes the reduction of molecular oxygen by different electron donors, recognizing phenolic compounds. The phenols oxidation by this enzyme is given by a sequence of reactions, where the phenols are converted to quinones and/or free radicals [17]. From this interaction between the enzyme and phenolic compound ( $17 \beta$-estradiol and estrone), the signal was recognized by the cantilever nanobiosensor, obtaining difference on the voltage.

As cantilever nanobiosensor sizes approach the nanoscale, their mechanical behavior starts resembling vibrational modes of molecules and atom. The mechanism of detection is based on the hormone absorption in the sensitive layer and the chemically induced surface stresses attributed to changes in Gibbs free energy. Second Lavrik, Sepaniak, and Datskos [18], the adsorption processes in the sensitive layer are driven by excess of the free interfacial energy, and the surface usually tends to expand that results in the reduction of the interfacial stress, denominated as compressive surface stress. This phenomenon was also related by Datskos and Sauers [19] in a cantilever coated in one side with gold layer. This process can be related that the result obtained by the cantilever nanobiosensor, since the voltage signal decrease with the hormone concentration increase (Fig. 3a).

The linear sensitivity was obtained in the range of 0.001 to $10 \mu \mathrm{g} / \mathrm{L}$ by the angular coefficient of concentration versus voltage of the hormones $17 \beta$-estradiol and estrone, and the values were 0.497 and $0.101 \mathrm{~V} / \mu \mathrm{g}$, respectively, with a regression coefficient above of 0.98 (Fig. 3b).

The limit of detection is defined as the lowest concentration of the analyte that can be distinguished by the sensor with a certain confidence level. In this work, the baseline value plus the multiple (3) of the standard deviation was used, which implies a confidence level of 99.6\%. The limit of detections found were 0.1 and $0.4 \mathrm{ng} / \mathrm{L}$ for $17 \beta$-estradiol and estrone, respectively. Taking in account the maximum limit allowed for phenolic compounds in drinking water $(3 \mu \mathrm{g} / \mathrm{L})$, according to Resolutions Conama 357/2005 and 430/2011 [20], it was observed that nanobiosensor could detect the presence of hormones satisfactory in liquid medium. 

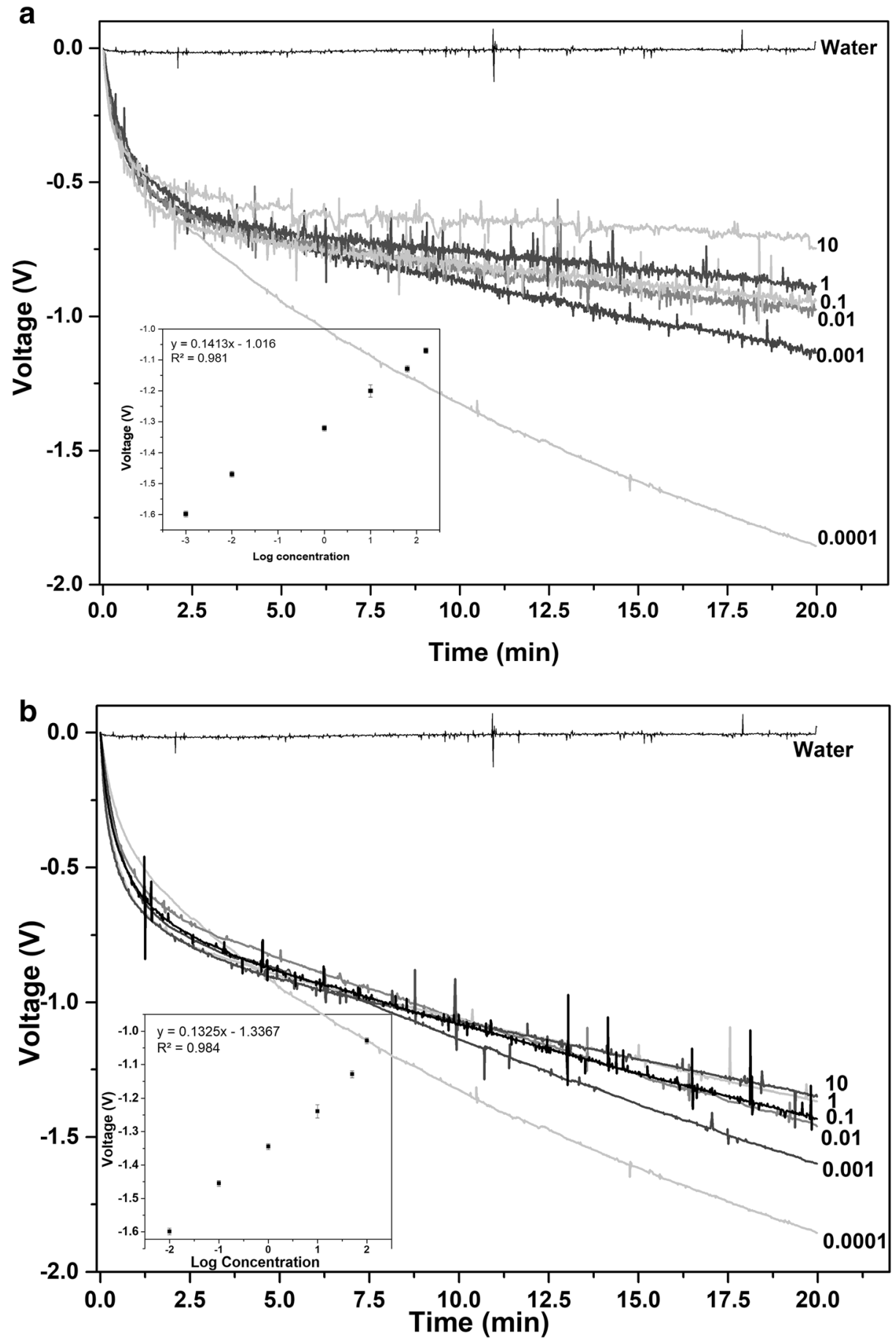

Fig. 3 Response of the cantilever nanobiosensor at ultrapure water and different concentrations of the hormones (a) $17 \beta$-estradiol and (b) estrone 


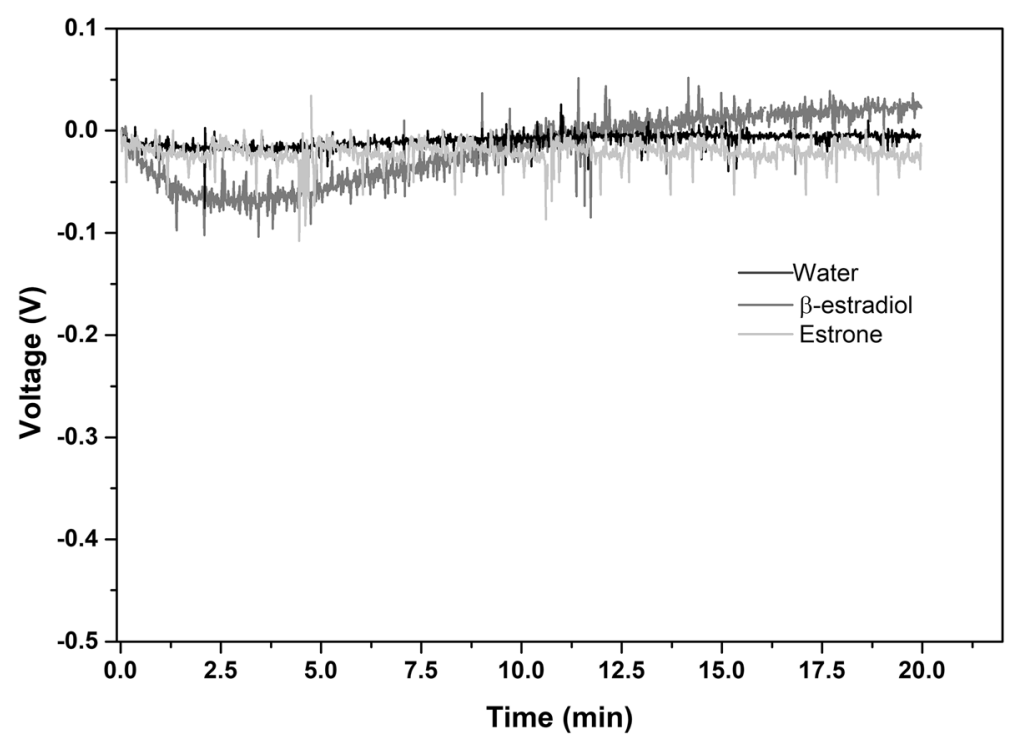

Fig. 4 Response of the uncoated cantilever at ultrapure water and with $1 \mu \mathrm{g} / \mathrm{L}$ of $17 \beta$-estradiol and estrone

By the annual average Environmental Quality Standards, the proposed limits in the water body are $0.4 \mathrm{ng} / \mathrm{L}$ for $17 \beta$-estradiol and $3.6 \mathrm{ng} / \mathrm{L}$ for estrone [21]. Take into account the detection limit obtained by the cantilever nanobiosensor, the device can be applied satisfactorily for endocrine disruptor detection in water samples.

Usually, analyses using gas chromatography-mass spectrometry or liquid chromatography with mass spectrometry are used to determine endocrine compounds in water at $\mathrm{ng} / \mathrm{L}$ to $\mu \mathrm{g} / \mathrm{L}$ levels. Daniel and de Lima [22] reported the determination of $17 \beta$-estradiol and estrone in natural water using solid-phase extraction and high-performance liquid chromatography (HPLC), obtaining a limit of detection of 1.62 and $1.57 \mu \mathrm{g} / \mathrm{L}$ for $\beta$-estradiol and estrone, respectively. Manickum, John, and Mlambo [23] using gas chromatography and mass spectrometric detection obtained a limit of detection of $5 \mathrm{ng} / \mathrm{L}$ for estrone and $5 \mathrm{ng} / \mathrm{L}$ for $17 \beta$-estradiol in ultrapure water matrix, respectively. Using high-performance liquid chromatographyfluorescence detection method for $17 \beta$-estradiol determination in aqueous standard solutions obtained a limit of detection of $2.5 \mathrm{ng} / \mathrm{L}$. Comparing the results obtained in the present work employing cantilever nanobiosensor with traditional methods was obtained a similar limit of detection. Thus, it was demonstrated that the developed device is adequate and is easy to apply.

Also, comparing the limit of detection found in surface waters in Brazil for the presence of endocrine disruptors, the nanobiosensor attends the values. In river water samples, Sodré, Locatelli, and Jardim [24] detected concentrations of $0.07 \mu \mathrm{g} / \mathrm{L}$ for estrone and $0.10 \mu \mathrm{g} / \mathrm{L}$ for $17 \beta$-estradiol. Moreira et al. [25] found concentrations levels between 5.6 to $63.8 \mathrm{ng} / \mathrm{L}$, and Torres et al. [26] found 28 and $137 \mathrm{ng} / \mathrm{L}$ to estrone and $17 \beta$-estradiol, respectively.

In order to verify the reversibility of the cantilever nanobiosensor, the experiment was repeated several times exposing to $1 \mu \mathrm{g} / \mathrm{L}$ of hormone solution and ultrapure water. Both responses returned to the initial condition (voltage) in all cycles evaluated using the same concentration (data not shown). The relative standard deviation (RSD \%) for both hormones presented values comprised between $2 \%$ which revealed that the nanobiosensor displayed acceptable reversibility. 
The long-term storage stability of nanobiosensor was investigated at $1 \mu \mathrm{g} / \mathrm{L}$ of each hormone. The device was stored at $4{ }^{\circ} \mathrm{C}$ and evaluated the response every 15 days, during 30 days. As observed in Fig. 5, the voltage responses of the nanobiosensor were kept constant and remained $98.8 \%$ of the original value after storage for 30 days. In this way, the results indicate that the nanobiosensor has excellent stability. This fact can be explained by the stabilization of the enzymatic bonds on the cantilever surface, which was formed during functionalization using the SAM technique, which is maintained throughout the storage time. In addition, the nanobiosensor presented stability in the response because it was stored at low temperature, maintaining the enzymatic activity. According to Stredansky [27], the storage stability can be affected by the humidity and high temperature that is considered the most negative factors in enzymatic biosensors. As a positive factor to good stability, the authors cited the immobilization effectively of employed enzymes.

In addition, when the surfaces modification or functionalization is performed with materials at the nanoscale, it can lead to a great surface area and enhancement of the optical properties, which can result in an increase sensitivity [28, 29]. According to Sassolas, Blum, and Leca-Bouvier [30], the immobilization affects the stability and the sensitivity of enzymatic biosensors, and the reproducibility and lifetime are drastically influenced by the enzyme stability in the support.

\section{Interference Study}

For this analysis, only the cantilever nanobiosensor functionalized with tyrosinase enzyme was used, and its selectivity was evaluated through the response measurements to three different substances (ascorbic acid, caffeine, and thiamine) as potential interferents, comparing the results with ultrapure water. Figure 6 shows the voltage response of the cantilever nanobiosensor in the presence of these substances.

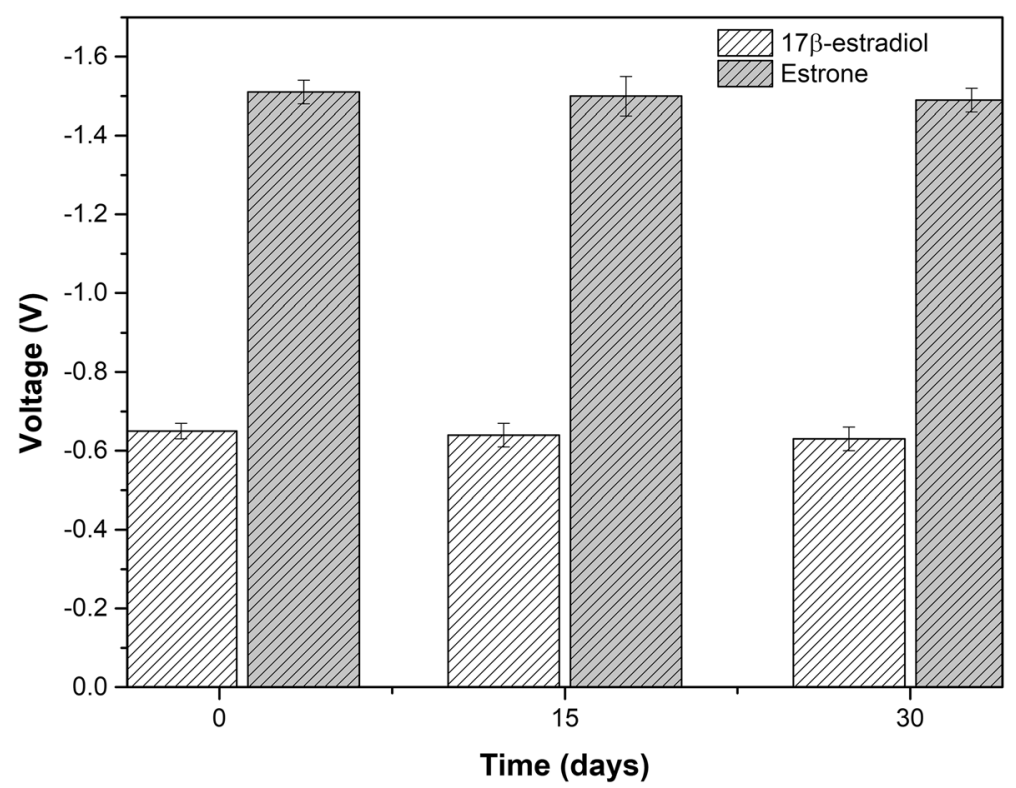

Fig. 5 The long-term storage stability of cantilever nanobiosensor as a function of different time interval at 1 $\mu \mathrm{g} / \mathrm{L}$ of $17 \beta$-estradiol and estrone 


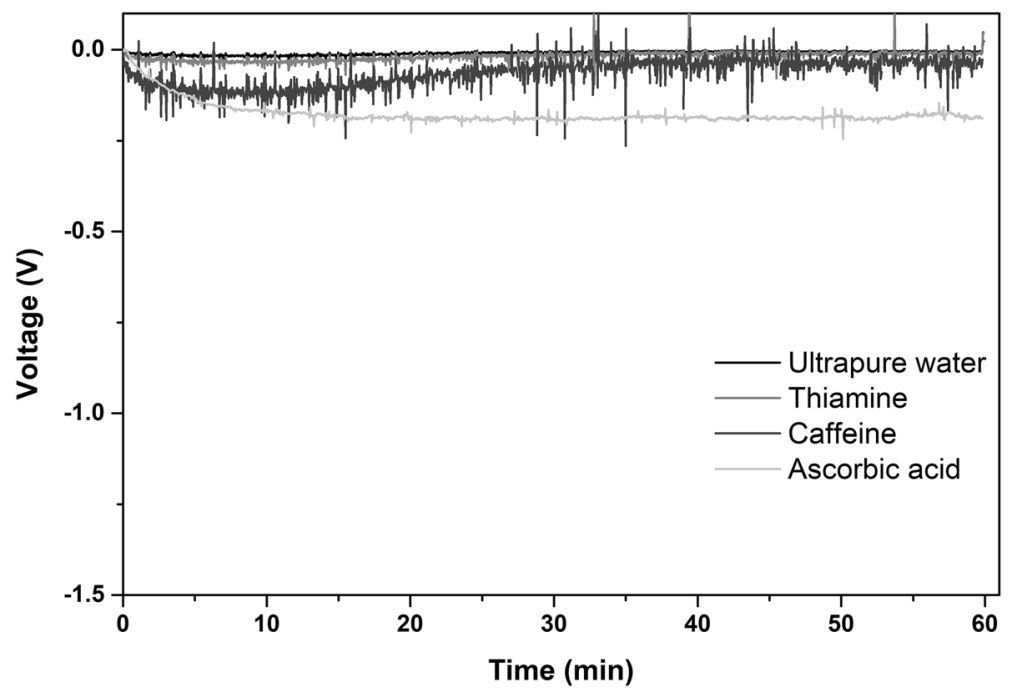

Fig. 6 Interference study of developed sensor system to ascorbic acid, caffeine, and thiamine substances

The results showed that the voltage signal for thiamine is close to ultrapure water indicating that this interference does not affect the cantilever nanobiosensor response. The caffeine presents a little change in the nanobiosensor signal, and the ascorbic acid has a more pronounced changed $(-0.18 \mathrm{~V})$. This voltage response may have been due to the high affinity and absorption capacity of ascorbic acid with the tyrosinase enzyme, as a function of the interaction with the $\mathrm{OH}$ groups [31]. Comparing this signal to the high concentration $(10 \mu \mathrm{g} / \mathrm{L})$ investigate of $17 \beta$-estradiol and estrone, the voltage signals obtained were -0.69 and $-1.34 \mathrm{~V}$, respectively. In this way, the signal obtained can be suggested that the cantilever nanobiosensor is selective to the hormones. The tyrosinase enzyme presents two activities in its catalytic cycle, one hydroxylates the monophenols to o-diphenols, and the other oxidizes o-diphenols to

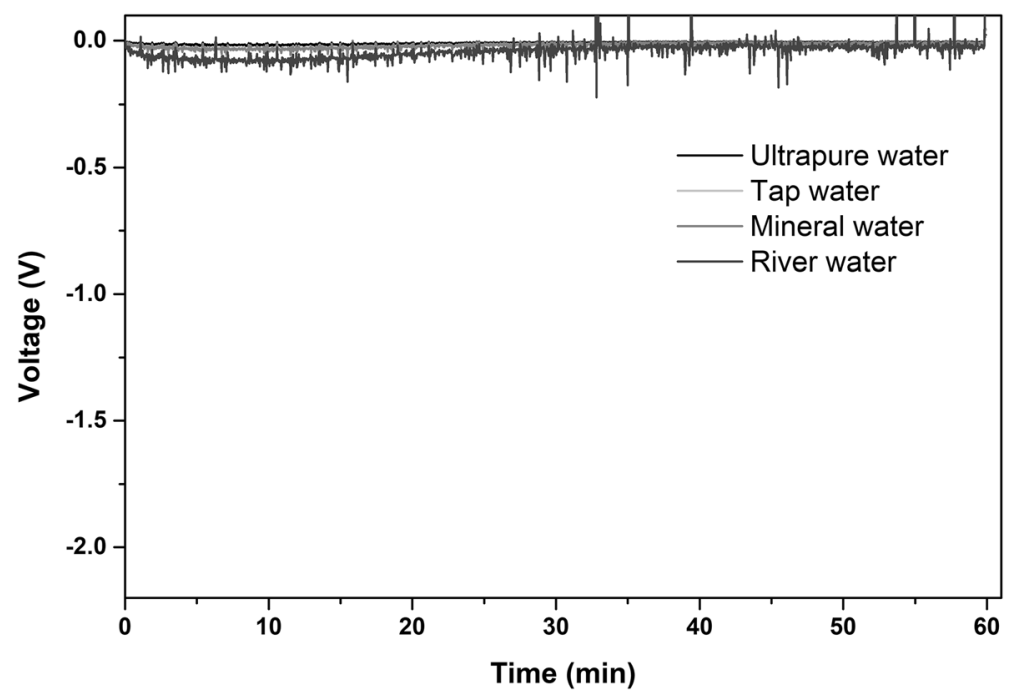

Fig. 7 Response in voltage of the cantilever nanobiosensor in water samples 
o-quinones [32], thus resulting in great affinity to phenolic compounds. The ascorbic acid has a synergic effect, since the optical isomers responsible for various redox reactions and the caffeine have weak interactions occupied with residues in the active region of the tyrosinase enzyme [33].

\section{Water Samples}

Figure 7 shows the behavior of the cantilever nanobiosensor functionalized with enzyme tyrosinase in contact with different water samples (ultrapure, river, tap, and mineral). It is observed that the voltage responses of the nanobiosensor to all analyzed samples were similar to the ultrapure water (blank). Therefore, these samples did not show the presence of hormone substance. Thus, it is possible to affirm that the nanobiosensor was able to detect water samples satisfactorily without prior preparation and purification of the samples, which makes faster analysis when compared to the chromatography technique, where pretreatment steps are required as extraction and derivatization in acidic and alkaline media [34].

\section{Conclusion}

In this work was presented a study with cantilever nanobiosensor functionalized with tyrosine enzyme applied in the detection of $17 \beta$-estradiol and estrone hormones in real samples. It was possible to verify that the high the concentration of the hormone presented, the great the voltage response. The nanobiosensor showed distinct voltage responses between the evaluated concentrations, with sensitivity of 0.497 and $0.101 \mathrm{~V} / \mu \mathrm{g}$, limit of detection of 0.1 and $0.4 \mathrm{ng} / \mathrm{L}$ for $17 \beta$-estradiol and estrone, respectively. Also, the develop device presented good reversibility, stability during storage, and no-showed signal losses during successive measurements. The SEM and PM-IRRAS analyses, as well as the topographic images obtained by AFM, allowed to follow the conformational changes of the surface along the functionalization stages, confirming the deposition of the sensitive layer on the cantilever surface. This cantilever nanobiosensor was successfully applied to the determination of $17 \beta$-estradiol and estrone in water samples. Therefore, the cantilever nanobiosensor developed could be readily extended toward the on-site monitoring of trace small molecular pollutants in environmental matrices.

Acknowledgments The authors would like to thank URI Erechim for the infrastructure.

Funding Information This study was financed in part by the Coordenação de Aperfeiçoamento de Pessoal de Nível Superior - Brasil (CAPES) - Finance Code 00,1, Cnpq, Fapergs, and Finep.

\section{Compliance with ethical standards}

Conflicts of Interest The authors declare that they have no conflict of interest.

\section{References}

1. Li, Y., Zhu, Y., Wang, C., He, M., \& Lin, Q. (2019). Selective detection of water pollutants using a differential aptamer-based graphene biosensor. Biosensors and Bioelectronics, 126, 59-67. https://doi.org/10.1016/j.bios.2018.10.047. 
2. Kase, R., Javurkova, B., Simon, E., Swart, K., Buchinger, S., Könemann, S., et al. (2018). Screening and risk management solutions for steroidal estrogens in surface and wastewater. TrAC Trends in Analytical Chemistry, 102, 343-358. https://doi.org/10.1016/j.trac.2018.02.013.

3. Vigneshvar, S., Sudhakumari, C. C., Senthilkumaran, B., \& Prakash, H. (2016). Recent advances in biosensor technology for potential applications - an overview. Frontiers in Bioengineering and Biotechnology, 4. https://doi.org/10.3389/fbioe.2016.00011.

4. Liu, S., Cheng, R., Chen, Y., Shi, H., \& Zhao, G. (2018). A simple one-step pretreatment, highly sensitive and selective sensing of $17 \beta$-estradiol in environmental water samples using surface-enhanced Raman spectroscopy. Sensors and Actuators B: Chemical, 254, 1157-1164. https://doi.org/10.1016/j. snb.2017.08.003.

5. Busayapongchai, P., \& Siri, S. (2017). Sensitive detection of estradiol based on ligand binding domain of estrogen receptor and gold nanoparticles. Analytical Biochemistry, 518, 60-68. https://doi.org/10.1016/j. ab.2016.11.003.

6. Alonso, J. M., Bielen, A. A. M., Olthuis, W., Kengen, S. W. M., Zuilhof, H., \& Franssen, M. C. R. (2016). Self-assembled monolayers of 1-alkenes on oxidized platinum surfaces as platforms for immobilized enzymes for biosensing. Applied Surface Science. https://doi.org/10.1016/j.apsusc.2016.05.006.

7. Della Ventura, B., Iannaccone, M., Funari, R., Pica Ciamarra, M., Altucci, C., Capparelli, R., \& Velotta, R. (2017). Effective antibodies immobilization and functionalized nanoparticles in a quartz-crystal microbalance-based immunosensor for the detection of parathion. PLoS One, 12(2), e 0171754. https://doi. org/10.1371/journal.pone.0171754.

8. Sýs, M., \& Vytřas, K. (2018). Tyrosinase electrochemical biosensors monitoring medicinally significant substances. Current Medicinal Chemistry, 25(33), 3988-4006. https://doi.org/10.2174 /0929867324666170727121327.

9. El Harrad, L., Bourais, I., Mohammadi, H., \& Amine, A. (2018). Recent advances in electrochemical biosensors based on enzyme inhibition for clinical and pharmaceutical applications. Sensors, 18(2), 164. https://doi.org/10.3390/s18010164.

10. Varmira, K., Mohammadi, G., Mahmoudi, M., Khodarahmi, R., Rashidi, K., Hedayati, M., \& Jalalvand, A. R. (2018). Fabrication of a novel enzymatic electrochemical biosensor for determination of tyrosine in some food samples. Talanta, 183, 1-10. https://doi.org/10.1016/j.talanta.2018.02.053.

11. Camargo, J. R., Baccarin, M., Raymundo-Pereira, P. A., Campos, A. M., Oliveira, G. G., Fatibello-Filho, O., \& Janegitz, B. C. (2018). Electrochemical biosensor made with tyrosinase immobilized in a matrix of nanodiamonds and potato starch for detecting phenolic compounds. Analytica Chimica Acta, 1034, 137143. https://doi.org/10.1016/j.aca.2018.06.001.

12. Zaidi, K. U., Ali, A. S., Ali, S. A., \& Naaz, I. (2014). Microbial tyrosinases: promising enzymes for pharmaceutical, food bioprocessing, and environmental industry. Biochemistry Research International, 2014, 1-16. https://doi.org/10.1155/2014/854687.

13. Marques De Oliveira, R., Ferreira, J., Santos, M. J. L., Faria, R. M., \& Oliveira, O. N. (2011). Probing the functionalization of gold surfaces and protein adsorption by PM-IRRAS. ChemPhysChem. https://doi. org/10.1002/cphc.201100080.

14. Tagliazucchi, M., De Leo, L. P. M., Cadranel, A., Baraldo, L. M., Völker, E., Bonazzola, C., \& Zamlynny, V. (2010). PM IRRAS spectroelectrochemistry of layer-by-layer self-assembled polyelectrolyte multilayers. Journal of Electroanalytical Chemistry. https://doi.org/10.1016/j.jelechem.2010.02.013.

15. Muenchen, D. K., Martinazzo, J., Brezolin, A. N., de Cezaro, A. M., Rigo, A. A., Mezarroba, M. N., Manzoli, A., Steffens, J., \& Steffens, C. (2018). Cantilever functionalization using peroxidase extract of low cost for glyphosate detection. Applied Biochemistry and Biotechnology, 186(4), 1061-1073. https://doi. org/10.1007/s12010-018-2799-y.

16. Martinazzo, J., Muenchen, D. K., Brezolin, A. N., Cezaro, A. M., Rigo, A. A., Manzoli, A., et al. (2018). Cantilever nanobiosensor using tyrosinase to detect atrazine in liquid medium. Journal of Environmental Science and Health - Part B Pesticides, Food Contaminants, and Agricultural Wastes, 53(4), 229-236. https://doi.org/10.1080/03601234.2017.1421833.

17. Lu, L., Zhang, L., Zhang, X., Huan, S., Shen, G., \& Yu, R. (2010). A novel tyrosinase biosensor based on hydroxyapatite-chitosan nanocomposite for the detection of phenolic compounds. Analytica Chimica Acta, 665(2), 146-151. https://doi.org/10.1016/j.aca.2010.03.033.

18. Lavrik, N. V., Sepaniak, M. J., \& Datskos, P. G. (2004). Cantilever transducers as a platform for chemical and biological sensors. Review of Scientific Instruments, 75(7), 2229-2253. https://doi.org/10.1063 /1.1763252.

19. Datskos, P. G., \& Sauers, I. (1999). Detection of 2-mercaptoethanol using gold-coated micromachined cantilevers. Sensors and Actuators B: Chemical, 61(1-3), 75-82. https://doi.org/10.1016/S0925-4005(99 )00251-8.

20. CONAMA. (2005). Resolução n 357, DE 17 DE MARÇO DE 2005. 
21. European Commission. (2012). Directive of the European parliament and of the council amending Directives 2000/60/EC and 2008/105/EC as regards priority substances in the field of water policy, COM (2011).

22. Daniel, M. D. S., \& De Lima, E. C. (2014). Determinação simultânea de estriol, $\beta$-estradiol, $17 \alpha$ etinilestradiol e estrona empregando-se extração em fase sólida (SPE) e cromatografia líquida de alta eficiência (HPLC). Ambiente e Agua - An Interdisciplinary Journal of Applied Science, 9(4). https://doi.org/10.4136/ambi-agua.1346.

23. Manickum, T., John, W., \& Mlambo, Z. D. (2016). Development and validation of a gas chromatographymass spectrometry test method for screening and quantitation of steroid estrogens (endocrine disruptor compounds) in water and wastewater using large volume injection. Annals of Chromatography and Separation Techniques, 2(2473-0696).

24. Sodré, F. F., Locatelli, M. A. F., \& Jardim, W. F. (2010). Occurrence of emerging contaminants in Brazilian drinking waters: a sewage-to-tap issue. Water, Air, and Soil Pollution, 206(1-4), 5767. https://doi.org/10.1007/s11270-009-0086-9.

25. Moreira, M., Aquino, S., Coutrim, M., Silva, J., \& Afonso, R. (2011). Determination of endocrinedisrupting compounds in waters from Rio das Velhas, Brazil, by liquid chromatography/high resolution mass spectrometry (ESI-LC-IT-TOF/MS). Environmental Technology, 32(12), 14091417. https://doi.org/10.1080/09593330.2010.537829.

26. Torres, N. H., Aguiar, M. M., Ferreira, L. F. R., Américo, J. H. P., Machado, Â. M., Cavalcanti, E. B., \& Tornisielo, V. L. (2015). Detection of hormones in surface and drinking water in Brazil by LC-ESI-MS/MS and ecotoxicological assessment with Daphnia magna. Environmental Monitoring and Assessment, 187(6), 379. https://doi.org/10.1007/s10661-015-4626-z.

27. Stredansky, M. (2017). Multienzyme amperometric gluconic acid biosensor based on nanocomposite planar electrodes for analysis in musts and wines. International Journal of Electrochemical Science, 1183-1192. https://doi.org/10.20964/2017.02.31.

28. Welch, C. M., \& Compton, R. G. (2006). The use of nanoparticles in electroanalysis: a review. Analytical and Bioanalytical Chemistry, 384(3), 601-619. https://doi.org/10.1007/s00216-005-0230-3.

29. Yogeswaran, U., \& Chen, S.-M. (2008). A review on the electrochemical sensors and biosensors composed of nanowires as sensing material. Sensors, 8(1), 290-313. https://doi.org/10.3390/s8010290.

30. Sassolas, A., Blum, L. J., \& Leca-Bouvier, B. D. (2012). Immobilization strategies to develop enzymatic biosensors. Biotechnology Advances, 30(3), 489-511. https://doi.org/10.1016/j.biotechadv.2011.09.003.

31. Silvério, M. D. O., Castro, C. F. S., \& Miranda, A. R. (2013). Avaliação da atividade antioxidante e inibitÃltextthreesuperiorria da tirosinase das folhas de Dipteryx alata Vogel (Baru). Revista Brasileira de Plantas Medicinais, 15, 59-65 Retrieved from http://www.scielo.br/scielo.php?script=sci_arttext\&pid= S1516-05722013000100008\&nrm=iso.

32. Zolghadri, S., Bahrami, A., Hassan Khan, M. T., Munoz-Munoz, J., Garcia-Molina, F., Garcia-Canovas, F., \& Saboury, A. A. (2019). A comprehensive review on tyrosinase inhibitors. Journal of Enzyme Inhibition and Medicinal Chemistry. https://doi.org/10.1080/14756366.2018.1545767.

33. Lee, K. E., Bharadwaj, S., Yadava, U., \& Kang, S. G. (2019). Evaluation of caffeine as inhibitor against collagenase, elastase and tyrosinase using in silico and in vitro approach. Journal of Enzyme Inhibition and Medicinal Chemistry, 34(1), 927-936. https://doi.org/10.1080/14756366.2019.1596904.

34. Liu, X., Wang, X., Zhang, J., Feng, H., Liu, X., \& Wong, D. K. Y. (2012). Detection of estradiol at an electrochemical immunosensor with a Cu UPD|DTBP-Protein G scaffold. Biosensors and Bioelectronics, 35(1), 56-62. https://doi.org/10.1016/j.bios.2012.02.002.

Publisher's Note Springer Nature remains neutral with regard to jurisdictional claims in published maps and institutional affiliations. 